\title{
BJOG yearly CME program
}

Name of the Article:

Review article: Dengue in Pregnancy

Page no (36)

Q.1 Write T or $\mathrm{F}$ regarding the statement mentioned below according to the review article.

a) Prevalence of Dengue in Bangladesh in 2000 was 5551

b) Worst outbreak occurred in 2002 and was 5500

c) From 2010 the incidence started to increase

d) In 2019, it increases 50,000

e) Highest serotypes of Dengue was DENV-3

Name of the Article:

Clinical Outcomes of Total Laparoscopic Hysterectomy (TLH): Seven Years' Experience in a Public Hospital.

\section{Page no (28)}

Q.2 Which of the following statements are T?

a. In Shaheed Suhrawardi Medical College Hospital TLH due to benign disease done in $80 \%$ cases.

b. In their series maximum size of the uterus was 36 week.

c. Mean operating time was 130 minutes.

d. Length of hospital stay was 2 days.

e. Most common urinary complication was uretero vaginal fistula $3(1 \%)$

Name of the Article:

"Histopathological findings of 100 cases of Abnormal Uterine Bleeding and their correlation with FIGO classification"

Page no (22)

Q.3 Which of the following statements are false according to above article? a. PALM-COEIN classification for causes of AUB was proposed by (FIGO) in 2015.

b. According to this article prevalence of menorrhagia in $\mathrm{DMCH}$ was $60 \%$.

c. Commonest cause of AUB was AUB-O

d. Commonest structural cause of $A U B$ was AUB-L

e. According to that article $40 \%$ AUB occur in adolescent and $60 \%$ in older than 45 years women.

Name of the Article:

Editorial: Abnormal Uterine Bleeding (AUB)

Page no (1)

Q.4 Special tests for diagnosis of AUB are-

a. Sonohysterography

b. TVS

c. Pap's Smear

d. Hysteroscope

e. Endometrial sampling for histopathology

Name of the Article:

"Immune thrombocytopenic purpura in pregnancy-a prospective observational study in a tertiary Care Centre"

Page no (15)

Q.5 Write T or F about the statements on this article mentioned below.

a. Total number of high risk patients from 20092017 at that department were 8000 .

b. Total number of ITP cases during that period were 50

c. Frequency of ITP among high risk cases are 5/ 1000 live births

d. $75 \%$ of the ITP cases were preexisting

e. Caesarean section rate of ITP with pregnancy were $90 \%$. 
Answer Sheet: BJOG yearly CME program: Examination: BJOG 2019: 34(1).

\section{CME on BJOG, 2019, 34(1): 1-67}

Please answer the questions on page .... by filling in the appropriate boxes below. Please mark the box for true answer and fill in the box until the letter is no longer visible. To process your exam, you must also provide the following information:

Name (in CAPITAL LETTER) Designation

Official Address

Mailing Address.

Mobile no.

E-mail.

OGSB Member No.

\begin{tabular}{|l|l|l|l|l|l|}
\hline Q 1 & A & B & C & D & E \\
\hline Q 2 & A & B & C & D & E \\
\hline Q 3 & A & B & C & D & E \\
\hline Q 4 & A & B & C & D & E \\
\hline Q5 & A & B & C & D & E \\
\hline Q 6 & A & B & C & D & E \\
\hline Q 7 & A & B & C & D & E \\
\hline Q 8 & A & B & C & D & E \\
\hline Q 9 & A & B & C & D & E \\
\hline Q 10 & A & B & & & \\
\hline
\end{tabular}

Evaluation form

Your completion of these CME activities includes evaluating them. Please respond to the questions below.

\begin{tabular}{|l|l|l|l|l|l|l|}
\hline 1. Please rate these activities (1- minimally, 5- completely) & 1 & 2 & 3 & 4 & 5 \\
\hline 1.1 & These CME activities are effective in meeting the educational objectives & & & & & \\
\hline 1.2 & These CME activities are appropriately evidence based & & & & \\
\hline 1.3 & These CME activities are relevant to my practice & & & & \\
\hline
\end{tabular}

\section{How many of your patients are likely to be impacted by what you learned from these activities?}

\begin{tabular}{|l|l|l|l|l|l|l|l|l|l|}
\hline$<20 \%$ & & $20 \%-40 \%$ & & $40 \%-60 \%$ & & $60 \%-80 \%$ & & $>80 \%$ & \\
\hline
\end{tabular}

3. Do you expect that these activities will help you improve your skill or judgment within the next 6 months? (1-definitely will not change, 5-definitely will change)

\begin{tabular}{|l|l|l|}
\hline \multicolumn{3}{|l|}{ 4. How will you apply what you learned from these activities (tick mark all that apply on the right of the statement): } \\
\hline 4.1 & In diagnosing patients & \\
\hline 4.2 & In monitoring patients & \\
\hline 4.3 & In educating students and colleagues & \\
\hline 4.4 & As part of a quality or performance improvement project & \\
\hline 4.5 & For Maintenance of board certification & \\
\hline 4.6 & In making treatment decisions & \\
\hline 4.7 & As a foundation to learn more & \\
\hline 4.8 & In educating patients and their caregivers & \\
\hline 4.9 & To confirm current practice & \\
\hline 4.10 & For maintenance of licensure & \\
\hline
\end{tabular}

- Please list at least one (1) change you will make to your practice as a result of this CME activity:

- How long did it take you to complete these activities?

...hours.

...minutes

- What, in your opinion, are the biggest clinical challenges related to obstetrics and gynecology? 